DOI 10.37882/2223-2974.2020.12.15

\title{
МЕХАНИЗМЫ ЭКОНОМИЧЕСКОГО СТИМУЛИРОВАНИЯ ПРОМЫШЛЕННЫХ КОМПАНИЙ К ПРИРОДООХРАННОЙ ДЕЯТЕЛЬНОСТИ, ВНЕДРЕНИЮ НАИЛУЧШИХ ДОСТУПНЫХ ТЕХНОЛОГИЙ И ПРИБЛИЖЕННЫХ К НИМ РЕШЕНИЙ: АНАЛИЗ ЗАРУБЕЖНОГО И РОССИЙСКОГО ОПЫТА
}

\section{MECHANISMS OF ECONOMIC STIMULATION OF INDUSTRIAL COMPANIES TO ENVIRONMENTAL PROTECTION ACTIVITIES, INTRODUCTION OF THE BEST AVAILABLE TECHNOLOGIES AND SOLUTIONS CLOSE TO THEM: ANALYSIS OF FOREIGN AND RUSSIAN EXPERIENCE}

\section{A. Zakondyrin}

Summary: At the present stage in various countries of the world, many measures are used to economically stimulate industrial companies to introduce and apply the best available technologies (BAT), as well as close to them and similar solutions. The study highlights the main economic instruments aimed at supporting environmental programs that are actively used abroad. It is concluded that many of the mechanisms of such incentives in our country are not applied at all or have not gained the necessary popularity and distribution for the current time stage. It is established that economic support measures aimed at the development of the BAT Institute in the Russian Federation relate mainly to industrial enterprises that are sources of increased negative impact on the environment (NVOS). It is concluded that support should be implemented not only in relation to these organizations, but also to their key suppliers and consumers of goods and services, for which it is proposed to provide special benefits that can be used if they comply with the conditions for cooperation with enterprises that have fully switched to BAT. The point of view is also expressed about the prospects of insuring the economic risks of creditors and investors of environmental programs and projects, as well as more active use of the opportunities of "green" bonds, which have become widespread in other countries of the world, but are still little used in Russia.

Keywords: best available technologies, foreign experience, environmental policy, environmental funds, payments for environmental pollution, environmental taxes, mandatory environmental insurance system, Institute of concession agreements, public private partnership, financing of environmental projects," green " bonds, quotas for environmental pollution.
Закондырин Александр Евгеньевич

Генеральный директор, Ассоциация разработчиков природоохранных технологий и экологических инициатив alexzakondyrin@gmail.com

Аннотация: На современном этапе в различных странах мира используется множество мер экономического стимулирования промышленных компаний к внедрению и применению наилучших доступных технологий (НДТ), а также приближенных к ним и аналогичных решений. В рамках исследования выделены основные экономические инструменты, нацеленные на поддержание экологических программ, активно используемые за рубежом. Сделан вывод о том, что многие механизмы такого стимулирования в нашей стране не применяются совсем или к текущему временному этапу не обрели должной популярности и распространения.

Установлено, что меры экономической поддержки, направленные на развитие института НДТ в Российской Федерации, касаются в основном промышленных предприятий - источников повышенного негативного воздействия на окружающую среду (НВОС). Сформулировано умозаключение о том, что поддержка должна быть реализована не только применительно к данным организациям, но также и к их ключевым поставщикам и потребителям товаров и услуг, для которых предложено предусмотреть специальные льготы, которые могут использоваться при соблюдении ими условия о сотрудничестве с предприятиями, полностью перешедшими на НдТ. Также выражена точка зрения о перспективности страхования экономических рисков самих кредиторов и инвесторов экологических программ и проектов, а также более активного использования возможностей «зеленых» облигаций, получивших широкое распространение в других странах мира, однако пока мало используемых в России.

Ключевые слова: наилучшие доступные технологии, зарубежный опыт, экологическая политика, экологические фонды, платежи за загрязнение окружающей среды, экологические налоги, система обязательного экологического страхования, институт концессионных соглашений, государственное частное партнерство, финансирование природоохранных проектов, «зелёные» облигации, квоты на загрязнения окружающей среды. 


\section{Ввеление}

$\mathrm{B}$ современном мире используется множество разнообразных мер экономического стимулирования промышленных компаний к реализации природоохранной деятельности, в том числе к внедрению и применению НДТ. Знание данных механизмов, а также возможность их качественной адаптации в России, способна в целом повысить общую эффективность экологопромышленной политики, реализуемой на территории нашей страны.

\section{1. Степень изученности тематики в научной литературе}

Международный опыт в сфере внедрения и применения наилучших технологий всё чаще привлекает внимание отечественных и зарубежных авторов. Освещение различных аспектов данного тематического направления происходит преимущественно в рамках отдельных публикаций в российской и зарубежной периодической печати. Как правило, особое внимание авторы уделяют вопросам, связанным с процедурами по определению НДТ в различных государствах мира, а также мерам и направлениям, реализуемых ими политик в сфере охраны окружающей среды [1 - 7].

Помимо статей, публикуемых непосредственно в журналах, важные вопросы рассматриваемой нами тематики освещаются также в специальных аналитических обзорах, в том числе, выпущенных Бюро НДТ, Центром экологической промышленной политики, а также иными авторитетными структурами и организациями России и иных стран мира [8 - 10].

Однако, несмотря на ценность такого рода работ, нами не найдено комплексных и фундаментальных исследований научного плана, выпущенных в форме монографий или диссертаций, полностью посвященных анализу зарубежного опыта в сфере внедрения и использования НДТ, а также приближенных к ним тех или иных управленческих и технологических решений.

Руководствуясь целями настоящей статьи, далее будет предпринята попытка проанализировать наиболее важные и ключевые аспекты выбранной тематической линии.

\section{2. Экономическое стимулирование развития института НАТ и иных направлений

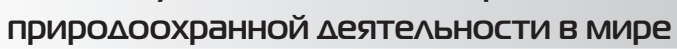

На современном этапе в мировой практике применяется множество разнообразных инструментов, направленных на стимулирование проектов в области охраны окружающей среды.
Среди наиболее распространенных и эффективных, следует выделить экологические налоги, виды которых в разных странах могут разниться между собой. Тем не менее, ключевые из них можно условно распределить на две большие группы:

а) Налоги, устанавливаемые на деятельность компаний, загрязняющих окружающих окружающую среду (реализация карательных мер по принципу - «природопользователь-загрязнитель должен платить»). Например, в Германии и некоторых иных государствах введен специальный налог на захоронение отходов. При этом в Италии, Нидерландах и Финляндии с 2014 года действует специальный налог на выбросы углерода.

б) Экологические акцизные налоги, которые включаются в общую цену самих товаров, загрязняющих атмосферный воздух, воду и (или) почву на этапах их производства и (либо) потребления. Например, в Австралии, Великобритании и ряде других государств взимается налог на пользование топливной и нефтяной продукцией; в Италии, Германии и Франции - на смазочные масла и др.

Помимо непосредственного введения и применения экологических налогов, налоговая политика в сфере природопользования нередко предполагает использование различных налоговых льгот и скидок, причем не только для наиболее экологически ответственных предприятий, но также и для потребителей и пользователей чистой с экологической точки зрения продукции и товаров.

Зачастую указанные экономические механизмы активно используются в автотранспортной сфере. К примеру, в Норвегии, Германии и Швеции на транспортные средства предусмотрены определенные налоговые скидки в зависимости от конкретных параметров таковых (наличия специальной экологической маркировки, года выпуска, объема двигателя и др.).

При этом во многих странах полученные от экологических налогов средства направляют на мероприятия в сфере развития технологий, сдерживающих и уменьшающих загрязнения окружающей среды, способствующих общему повышению уровня ресурсосбережения.

Платежи за загрязнение окружающей среды направляются компаниями-природопользователями в бюджеты своих стран за выбросы загрязняющих веществ в атмосферу, сбросы в водоемы сточных вод, складирование ТО (твердых отходов). Однако следует пояснить, что для достижения стимулирующего результата ставки по ним должны быть существенно выше самих затрат, необходимых для реализации соответствующих природоохранных мероприятий. В противном случае компаниям будет выгодней производить соответствующие отчисле- 
ния, нежели чем уменьшать уровень вредных выбросов как таковых.

При этом вносимые на постоянной основе такого рода платежи могут вести не только к позитивным, но и негативным последствиям, так как способны в целом отрицательно повлиять на состояние окружающей среды. По отмеченной причине в экономически развитых странах Запада данный механизм не обрел большой популярности и широкого распространения.

Более эффективными представляются платежи за использование муниципальных очистных сооружений. В ряде государств они учитываются при разработке тарифных планов на муниципальные услуги.

При этом во многих странах, помимо перечисленных выше экономических инструментов, также активно применяются и специальные штрафы за загрязнения окружающей среды. Данная мера в отношении компаний-загрязнителей, как правило, используется при крупных техногенных катастрофах и авариях (например, таких как произошедший в 2010 году в Мексиканском заливе разлив нефти), а также в других случаях, когда имели место те или иные серьезные нарушения экологического баланса.

Мы убеждены, что своевременное внедрение ВАТ (НДТ), а также аналогичных им решений, во многих случаях могло бы предотвратить подобные аварии, катастрофы и иные экологические проблемы.

Финансирование и софинансирование различных природоохранных проектов на уровне государства, реализуемое путем выдачи субсидий, дотаций, реализации государственных программ экономической помощи, выдачи грантов и т.д. Например, в рамках данного направления экономического стимулирования компаниям Швеции предоставляются специальные субсидии, нацеленные на поддержание строительства сооружений, предназначенных для утилизации ТО (твердых отходов). Размер такой помощи может достигать половины стоимости самих этих сооружений. При этом предприятиям Германии выделяются суммы для возмещения до 50\% понесенных затрат на модернизацию природоохранных технологий с учетов требований к НДТ или иным аналогичным решениям.

К эффективным экономическим инструментам, нацеленным на стимулирование к деятельности в сфере охраны окружающей среды, активно применяемым в практике ряда зарубежных стран, также относится и торговля квотами или правами (лицензиями) на загрязнение.

Необходимо отметить, что упомянутая мера имеет безусловный рыночный характер. Однако есть и некоторые негативные последствия. В частности, следует пояснить, что данный процесс, в числе прочего, способствует сдерживанию естественного развития рыночной конкуренции на ряде территорий, так как затрудняет выход на рынок новых промышленных предприятий - потенциальных загрязнителей окружающей природы.

В Дании, Соединенных Штатах Америки, Германии, а также в некоторых иных странах мира новые промышленные компании обязаны соблюдать определенные повышенные требования, указанные в специальных экологических нормативах, применяя наиболее современные технологии. В свою очередь, отмеченные условия ставят их в потенциально неравную конкурентную ситуацию (с позиции требуемых затрат) с другими предприятиями уже функционирующими на рынке более продолжительное время.

Еще одним стимулирующим инструментом реализации природоохранных политик многих государств являются «зелёные» или экологические облигации.

Поясним, что данные ценные бумаги могут выпускаться муниципальными и государственными органами власти, международными финансовыми структурами, крупными корпорациями и др. Использование отмеченного инструмента направлено на финансирование различных проектов в области охраны окружающей среды.

К примеру, еще с 1980 годов в Соединенных Штатах Америки корпорации выпускают экологические облигации в целях поддержки строительства специальных очистных сооружений. В целом в последние годы в экономике многих стан наблюдается очевидный повышенный интерес к данному инструменту. При этом спрос на корпоративные «зелёные» облигации во многих странах существенно возрос.

Другим не менее популярным механизмом стимулирования природоохранных проектов, используемым в некоторых западных государствах, представляется так называемая система возмещения в виде векселей или залогов. В отмеченной схеме предприятия, производящие недостаточно экологичную продукцию, берут на себя специальные обязательства в области повышения степени экологичности таковой. Для реализации соответствующих мероприятий устанавливаются конкретные сроки. Если компаниям удается выполнить обязательства - залоговая сумма возвращается им обратно. В противоположном случае - не возвращается, но направляется на реализацию различных проектов в сфере охраны и восстановления окружающей среды.

В ряде экономически развитых государств некоторое распространение получила и мера в форме доброволь- 
ного страхования ответственности за возмещение возможных ущербов от аварийных загрязнений окружающей среды. При этом в Бельгии, Швеции, Нидерландах и некоторых других государствах мира внедрена и активно функционирует система обязательного экологического страхования, реализуемого частными страховыми организациями и структурами.

Другим экономическим инструментом, направленным на стимулирование промышленных компаний к природоохранной деятельности, представляется использование возможностей института кониессионных соглашений, а также специальных механизмов государственного частного партнерства. Так, например, в Австралии, США, Великобритании, Канаде, Финляндии, Франции, Испании и некоторых других государствах мира природоохранные программы в горнодобывающей промышленности, а также в области утилизации отходов осуществляются по договорам концессии. При этом зачастую в концессию передают бизнес в сфере переработки ТБО (твердых бытовых отходов).

Не менее важная роль в осуществлении соответствующих проектов принадлежит и экологическим фондам. Чаще всего такого рода организации представлены государственными внебюджетными фондами, а также негосударственными структурами, аккумулирующими финансы за счет международных, а также государственных грантов. Средства накапливаются и за счет специальных налогов, которые направляются на мероприятия в области охраны окружающей среды. В качестве главной цели формирования экологических фондов выступает финансирование особо охраняемых объектов природы, в том числе парков национального значения и других важных территорий.

\section{3. Внедрение НАТ в России: меры экономического стимулирования и государственной поцАержкКи}

Российским законодательством также предусмотрен ряд мер государственной поддержки, направленной на стимулирование отечественных компаний к активному внедрению и применению НДТ. Среди наиболее действенных механизмов можно выделить такие направления экономической помощи как:

- предоставление льгот в отношении платы за НВОС (Ф3 от 21.07.2014 № 219-Ф3) [11];

- полный отказ от взимания такой платы (коэффициент «ноль») для промышленных компаний I класса опасности, внедривших НДТ, а также II категории НВОС, относящихся к сферам обязательного использования НДТ;

- применение для оборудования уровня НДТ специального амортизационного коэффициента «2» (распоряжение Правительства РФ № 1299-р от
20.07.2017);

- налоговый инвестиционный кредит [12] и др.

Заметим, что положения, прописанные в Распоряжении Правительства РФ от 30.04.2019 г. № 541, дополнили данный перечень некоторыми возможностями в области применения такого нового для российской практики стимулирующего инструмента, как экологические или «зелёные» облигации [13].

Следует напомнить, что данный инструмент активно применяется в ряде зарубежных стран мира. Однако, несмотря на его закрепление в отечественной нормативно-правовой базе, в России он еще не обрел достаточной популярности и широкого распространения, что мы считаем упущением.

Убеждены, что отмеченный механизм требует дополнительных адаптаций и корректив с учетом целей реализуемой эколого-промышленной политики России, особенностей экономического состояния страны, специфики функционирования отечественных институтов, менталитета и отношения потенциальных инвесторов к конкретным финансовым инструментам и механизмам.

Необходимо пояснить, что на сегодняшний день в Российской Федерации в роли основных инвесторов, участвующих в процессах по внедрению наилучших доступных технологий, выступают действующие акционеры и учредители самих промышленных предприятий источников НВОС. Экономические выгоды, получаемые компаниями в случае перехода на НДТ в форме экономии платы за загрязнения окружающей среды, выражаются в повышенных дивидендах самих акционеров. Вместе с тем практически не используется множество иных механизмов активизации запущенных здесь процессов.

Мы убеждены, что на современном этапе назрела острая необходимость в расширении перечня используемых мер экономического стимулирования. Помимо адаптации и активизации механизма «зелёных» или экологических облигаций, также рекомендуем уменьшение общего количества реализуемых проверок в отношении экологически ответственных организаций, использование дополнительных льгот при кредитовании лучших экологических программ, установление низкопроцентных ставок и др.

Также некоторый эколого-экономический результат можно ожидать и при формировании специальных фондов, в том числе создаваемых за счет частных капиталов. Деятельность данных фондов будет нацелена на поощрение предприятий, внесших наибольший вклад в развитие российского рынка наилучших доступных технологий, а также самих организаций - источников загрязнений окружающей среды, внедривших за опти- 
мально короткие сроки оборудование НДТ. Кроме того, поощрительные меры могут быть реализованы в отношении иных компаний, научных институтов и центров, достигших тех или иных наиболее выдающихся результатов в природоохранной сфере.

Помимо прочего, подчеркнем и то, что на сегодняшний день меры экономического стимулирования, направленные на развитие сферы НДТ в России, осуществляются преимущественно в отношении лишь крупных предприятий - источников I категории НВОС.

Однако мы твердо убеждены в том, что экономическая поддержка должна быть реализована не только в отношении этих компаний, но также их основных потребителей продукции и поставщиков. Для данных категорий организаций также предлагаем предусмотреть экономические льготы, по аналогии с практикой некоторых зарубежных государств. При этом поощрительные меры могут использоваться в случае сотрудничества этих предприятий с наиболее ответственными в экологическом плане компаниями, полностью модернизировавшими свое производство в соответствии с принципами НДТ. Также в качестве перспективного направления стимулирования природоохранной деятельности видим внедрение специальных мероприятий, нацеленных на активизацию страхования экономических рисков самих кредиторов и инвесторов различных экологических проектов и программ, в том числе направленных на внедрение НДТ, а также разработку новых перспективных технологий.

\section{Зак^ючение}

Подводя итоги настоящей статьи, можно констатировать, что использование в различных станах мира разнообразных инструментов экономического стимулирования компаний к реализации природоохранных мероприятий в целом ведет к формированию рыночной среды и конкурентной инфраструктуры, открытию экологических бирж, кредитно-финансовых учреждений, специализированных фондов, консалтинговых, посреднических, а также иных организаций и структур.

Однако на современном этапе в нашей стране используется далеко не весь перечень возможных экономических инструментов. Ряд финансовых институтов, хоть и закреплен официально на уровне законодательства, тем не менее, до сих пор не получил должного распространения в российской практике. Убеждены, что только взвешенная и хорошо продуманная система экономического стимулирования может обеспечить дополнительный инвестиционный приток для восполнения имеющегося финансового дефицита.

Полагаем, что отечественные схемы, применяемые для стимулирования перехода промышленности на принципы наилучших доступных технологий, целесообразно рассматривать через призму прозрачности, а также стремления к упрощению процедур по подаче заявок на получение заемных средств, налоговых и любых иных льгот. В свою очередь, это позволит уменьшить нагрузку отчетного и административного характера, причем как на частный сектор, так и на государство в целом.

\section{ЛИТЕРАТУРА}

1. Гурьева М.А. Экологизация экономики: международный опыт // Армия и общество. - 2012. - С. 13-17.

2. Кирсанова Е.Г., Бондарева А.Г. Использование экологических инноваций как фактор решения экологических проблем: отечественный и зарубежный опыт // Русская политология. - 2017. - № 3. - С. 57-63.

3. Суворова Ю.В., Сергиенко О.И. Применение европейского опыта идентификации наилучших доступных технологий на российских предприятиях пивоваренной отрасли // Современные тенденции развития науки и технологий. - 2015. - № 1-2. - С. 123-125.

4. Тяглов С.Г., Воскресова Г.Н. Особенности определения технологии в качестве НДТ: российский и зарубежный опыт // Journal of economic regulation. - 2019. - № 2. - T. 10. - C. 96-112.

5. Evrard D., Villot J., Armiyaou C., Laforest V., Gaucher R., Bouhrizi S. Best Available Techniques: An integrated method for multicriteria assessment of reference installations // Journal of Cleaner Production. - 2018. - Vol. 176. - PP. 1034-1044.

6. Jamrozik A., Wisniowski R., Gonet A. The best available techniques for the control of solid and treatment of oil-contaminated drilling waste // Conference proceedings: 19th international multidisciplinary scientific geoconference SGEM 2019. - PP. 1099-1108.

7. Gasho E.G., Gasho I.A. Economics and ecology symbiosis: transition to principles of Best Available Techniques // Journal of physics: conference series. - 2018. - PP. $22-24$.

8. Наилучшие доступные технологии. Предотвращение и контроль промышленного загрязнения. Этап 2: Подходы к определению наилучших доступных технологий (НДТ) в странах мира / Управление по окружающей среде, здоровью и безопасности Дирекции по окружающей среде ОЭСР. Пер. с англ. Москва, 2018.

9. Наилучшие доступные технологии. Предотвращение и контроль промышленного загрязнения. Этап 3: Оценка действенности политик в сфере НДТ / Управление по окружающей среде, здоровью и безопасности Дирекции по окружающей среде ОЭСР. Пер. с англ. - Москва, 2019.

10. Экономические инструменты стимулирования перехода на НДТ в странах Европейского Союза: аналитическое исследование / И. Галларага, А. Маркан- 
дия, А. Аверченкова. Под общ. ред. М.В. Бегак. - М., 2019.

11. Федеральный закон «0 внесении изменений в Федеральный закон "0б охране окружающей среды" и отдельные законодательные акты Российской Федерации» от 21.07.2014 № 219-Ф3 (в ред. от 26.07.2019) // КонсультантПлюс.

12. Распоряжение Правительства РФ от 20.06.2017 № 1299-р (ред. от 31.03.2020) «06 утверждении перечня основного технологического оборудования, эксплуатируемого в случае применения наилучших доступных технологий, в целях применения подпункта 5 пункта 1 статьи 259.3 Налогового кодекса РФ» // КонсультантПлюс.

13. Постановление Правительства РФ от 30.04.2019 № 541 «0б утверждении Правил предоставления субсидий из федерального бюджета российским организациям на возмещение затрат на выплату купонного дохода по облигациям, выпущенным в рамках реализации инвестиционных проектов по внедрению наилучших доступных технологий» // СПС «КонультантПлюс».

(с) Закондырин Александр Евгеньевич (alexzakondyrin@gmail.com).

Журнал «Современная наука: актуальные проблемы теории и практики» 